\title{
Gambaran Komunikasi Interpersonal Petugas Pendaftaran Pasien Terhadap Kepuasan Pelayanan di Puskesmas Karang Pule
}

\author{
Syamsudin ${ }^{1}$, Ria Rahmatul Istiqomah ${ }^{2 *}$, Heru Purnama ${ }^{3}$ \\ ${ }^{1,2,3)}$ Politeknik Medica Farma Husada Mataram \\ E-mail : 'riarahmatulistiqomah88@gmail.com, ${ }^{2}$ syamsudin01@gmail.com, \\ ${ }^{3}$ herupurnama@gmail.com
}

\begin{abstract}
ABSTRAK
Komunikasi interpersonal adalah komunikasi yang terjadi antara dua atau lebih, yang biasanya tidak diatur secara formal. Kepuasan jasa kesehatan tercapai jika apa yang didapatkan pasien melebihi harapannya. Rancangan penelitaian ini adalah deskriptif kuantitatif yang bertujuan untuk melihat gambaran kepuasan pasien dalam meningkatka kualitas pelayananya. Variabel penelitian ini adalah kepuasan pasien terhadap pelayanan di puskesmas Karang Pule Kota Mataram yang meliputi loket pendaftaran dengan subvariabe empati, keterbukaan, kesetaraan dan dukungan. Untuk mengidentifikasi tingkat kepuasan pasien terhadap proses pelayanan oleh petugas pendaftaran pasien di Puskesmas Karang Pule Kota Mataram, berdasarkan 4 sikap komunikasi interpersonal yaitu empati, keterbukaan, kesetaraan dan dukungan. Metode penelitian ini adalah deskriptif kuantitatif merupakan pengamatan yang bersifat ilmiah serta dilakukan secara hati-hati dan cermat sehingga hasilnya menjadi lebih akurat dan tepat. Populasi penelitian adalah pengunjung Puskesmas Karang Pule Kota Mataram pada bulan Desember 2018. Metode pengambilan sampel dengan Rumus slovin. Sampel diambil 97 pasien di Puskesmas Karang Pule Kota Mataram dengan teknik analisis data menggunakan pendekatan cross sectional. Hasil penelitian dianalisis dengan membandingkan harapan dan pengalaman yang menggambarkan tingkat kepuasan pasien terhadap pelayanan kesehatan dalam aspek empati 57,8\%, keterbukaan 58,7\%, kesetaraan 57,8\%, dan dukungan 56,7\%. Tingkat kepuasan pasien secara keseluruhan, 69,1\% di kategorikan sangat puas. Kesimpulan penelitian yang dilakukan di Puskesmas Karang Pule menunjukan hasil kualitas pelayanan yang diberikan oleh Puskesmas tersebut memuaskan.
\end{abstract}

Kata kunci: Komunikasi Interpersonal, Pelayanan Kesehatan, Tingkat Kepuasan Pasien

\section{ABSTRACT}

Interpersonal communication is communication that occurs between two or more, which is usually not formally regulated. Satisfaction of health services is achieved if what the patient gets exceeds his expectations. The design of this research is quantitative descriptive that aims to see the picture of patient satisfaction can further improve the quality of service. The variables of this study were patient satisfaction with services in Karang Pule Health Center in Mataram City which included registration counters with subvariables of empathy, openness, equality and support. To identify the level of patient satisfaction with the service process by the patient registration officer at the Karang Pule Health Center in MataramCity, based on 4 interpersonal communication attitudes namely empathy, openness, equality and support. To find out the picture of interpersonal communication on patient satisfaction at the service at Karang Pule Health Center, Mataram City.This research method is quantitative descriptive is a scientific observation and is carried out carefully and carefully so that the results are more accurate and precise. The study population was visitors to the Karang Pule Health Center in Mataram City in December 2018. The sampling method was using the Slovin formula. Samples were taken 97 patients in PuskesmasPularang, Mataram City. Data analysis techniques used a cross sectional approach. The conclusion of the research conducted Karang Pule Puskesmas showed that the quality of services provided by the Puskesmas was saticsfactory.

Keywords: Interpersonal Communication, Health Services, Patient Satisfaction Level

*Korespondensi Author : Ria Rahmatul Istiqomah, Politeknik Medica Farma Husada Mataram, E-mail : riarahmatulistiqomah88@gmail.com,Telp.082144545962 


\section{PENDAHULUAN}

Puskesmas adalah organisasi kesehatan fungsional yang merupakan pusat pengembangan kesehatan masyarakat yang juga membina peran serta masyarakat dan memberikan pelayanan secara menyeluruh dan terpadu kepada masyarakat di wilayah kerjanya dalam bentuk kegiatan pokok (Depkes RI, 2014). Dengan kata lain puskesmas mempunyai wewenang dan tanggungjawab atas pemeliharaan kesehatan masyarakat dalam wilayah kerjanya. Menurut Kepmenkes RI No. 128/Menkes/SK/II/2004 puskesmas merupakan Unit Pelayanan Teknis Dinas kesehatan kabupaten/kota yang bertanggung jawab menyelenggarakan pembangunan kesehatan di suatu wilayah kerja.

Masyarakat telah menganggap bahwa puskesmas adalah harapan kedua sebelum Rumah sakit bagi orang yang sedang sakit bahkan ada sebagian masyarakat yang cepatcepat ingin berobat ke puskesmas sebelum ke Rumah sakit. Jika mereka menderita suatu penyakit agar tercapai tingkat kesehatan yang berkualitas puskesmas mengupayakan itu dengan meningkatkan berbagai fasilitas pelayanan (Hazimah, dalam Kamila 2018).

Pelayanan kesehatan yang diberikan puskesmas merupakan pelayanan kesehatan yang menyeluruh yang meliputi pelayanan kuratif (pengobatan), preventif (pencegahan), promotif (peningkatan kesehatan), dan rehabilitatif (pemulihan kesehatan). Pelayanan tersebut ditujukan kepada semua penduduk dengan tidak membedakan jenis kelamin dan golongan umur, sejak dari pembuahan dalam kandungan sampai tutup usia (Effendi, 2009).

Agar pelayanan kesehatan dapat berjakan dengan efektif dan efisien, keberadaan puskesmas harus di tunjang dengan tempat pendaftarn pasien.Pendaftaran pasien adalah pelayanan rutin untuk menerbitkan urutan pelayanan dan memudahkan pelayanan dan memudahkan mendapatkan informasi rekam medis bagi seluruh fasilitas pelayanan yang tersedia di puskesmas yang di mulai dari persiapan, kedatangan pasien, sampai dengan pengiriman kartu rekam medis masing-masing PUSLITBANG Sinergis Asa Professional, Jember unit pemeriksaan, kemudian mengembalikan lagi kartu rekam medis ke dalam tempat semula (Kuntoro,2017)

Berdasarkan hasil penelitian Kuntoro \& Istiono (2017) serta Linda (2018) bahwa tingkat kepuasan pasien diukur dari 5 dimensi mutu, yaitu: Reliability (kehandalan), Responsiveness (cepat tanggap), Assurance (jaminan), Empathy (empati), dan Tangibles (berwujud). Sementara penelitian yang akan saya lakukan diukur dari 4 dimensi komunikasi interpersonal yaitu Empati, Keterbukaan, Kesetaraan dan Dukungan yang akan dilakukan dalam penelitian ini.

Pelayanan pendaftaran pasien harus mampu mencakup informasi penting mengenai data sosial pasien. Selain itu petugas pelayanan sebaiknya berpenampilan rapi dan berkomunikasi aktif. Dalam hal ini kemampuan komunikasi interpersonal merupakan salah satu faktor pendukung dalam proses pelayanan.

Komunikasi merupakan softskill atau kemampuan dasar yang harus dimiliki oleh petugas pelayanan guna mempertahankan pelanggan/pasien dan meningkatkan pelanggan/pasien, aktivitas dalam kualitas pelayanan berawal dari kemampuan komunikasi interpersonal petugas pelayanan.

Tata cara melayani pasien dapat dinilai baik bilamana dilaksanakan oleh petugas dengan cepat, sikap yang ramah,empati, sopan, tertib dan penuh tanggung jawab. Untuk menciptakan dan menjaga mutu pelayanan medis yang sesuai dengan keinginan masyarakat, maka pihak puskesmas perlu suatu umpan baik dari masyarakat yaitu tanggapan dan penilaian dari para pasien sehingga dijadikan sebagai suatu bahan evaluasi dan gambaran apakah pelayanan yang diberikan telah memenuhi kepuasan pasien atau belum.

Berdasarkan hasil observasi awal yang dilakukan di Puskesmas Karang Pule dari 6 pasien tersebut, hanya 2 pasien yang mengatakan puas dengan pelayanan yang ada di Puskesmas Karang Pule Kota Mataram, karena dengan adanya puskesmas ini mereka bisa mengetahui jenis penyakit yang dideritanya dan dengan adanya puskesmas ini bisa membantu kami. Dan 4 lainya mengatakan kurang puas 
dalam pelayanan karena petugasnya lambat, tempat tunggu pasiennya tidak rapi dan bersih serta bahasa yang digunakan dalam pelayanan kaku dan tidak ramah. Komunikasi yang dilakukan dengan pasien memiliki dampak terhadap kepuasan pasien, sehingga tujuan utama dari komunikasi untuk menciptakan hubungan interpersonal yang baik,memfasilitasi pertukaran informasi. Pelayanan komunikasi interpersonal dapat dilihat dari dimensi empat dimensi yaitu : empati, keterbukaan, kesetaraan dan dukungan.

Kepuasan pasien didefinisikan sebagai respon pelanggan terhadap ketidaksesuaian antara tingkat kepentingan sebelumnya dan kinerja aktual yang dirasakannya setelah pemakaian. Kepuasan pasien adalah inti dari pemasaran yang berorientasi kepada pasien. Pelayanan yang memuaskan dan berkualitas akan membentuk loyalitas pasien, dan kepuasan sangat erat hubungannya dengan "word of mouth", maka pelayanan yang memuaskan tersebut juga akan mendatangkan pasien baru. Efek selanjutnya akan berlanjut pada proses terbentuknya citra puskesmas yang meningkat. Oleh karena persaingan dalam pelayanan kesehatan yang sangat ketat, serta untuk menjadikan puskesmas sebagai layanan kesehatan tingkat pertama bagi tercapaianya puskesmas sehat 2012. Maka setiap puskesmas akan berusaha untuk menempatkan dirinya sebaik mungkin dimata pasienya agar dapat dipercaya untuk memenuhi kebutuhannya dalam bidang kesehatan (Rangkuti, 2013).

Memperhatikan masalah diatas peneliti tertarik untuk melakukan penelitian tentang pelayanan di tempat pendaftaran pasien di Puskesmas Karangpule. Mengetahui kepuasan pasien diharapkan pelayanan di pendaftaran pasien dapat dimaksimalkan, sehingga pada akhirnya puskesmas tersebut dapat memberi pelayanan yang berkualitas sekaligus memenuhi harapan dan kepuasan pasien.

\section{METODOLOGI}

Berikut ini metodologi yang dilakukan dalam penelitian :

\section{Desain Penelitian}

Penelitian ini menggunakan jenis penelitian deskriptif. Menurut Morissan (2012), penelitian deskriptif merupakan pengamatan yang bersifat ilmiah serta dilakukan secara hatihati dan cermat sehingga hasilnya menjadi lebih akurat dan tepat. Penelitian ini bertujuan untuk mengetahui tingkat kepuasan pasien di tempat pendaftaran di Puskesmas Karang Pule Kota Mataram. Jenis penelitian ini menggunakan pendekatan kuantitatif. Penelitian ini dilaksanakan di Puskesmas Karang Pule Kota Mataram pada bulan Desember 2018.

Dalam penelitian yang menjadi variabel independen adalah komunikasi interpersonal petugas. Variabel independen sering disebut dengan variabel bebas. Variabel bebas merupakan variabel yang mempengaruhi atau yang menjadi sebab atau perubahanyaatau timbulnya variabel dependen (terikat) (Natoatmodjo, 2010). Sedangkan variabel dependen sering disebut varibel terikat merupakan variabel yang dipengaruhi atau yang menjadi akibat, karena adanya variabel bebas (Natoatmodjo, 2010). Dalam penelitian ini yang menjadi variabel dependen adalah kepuasaan pasien terhadap pelayanan.

\section{Populasi dan Sampel}

Populasi merupakan subyek penelitian menurut (Sugiyono 2010). Populasi adalah wilayah generalisasi yang terdiri atas obyek/subyek yang mempunyai kualitas dan karakteristik tertentu yang ditetapkan oleh peneliti untuk mempelajari dan ditarik kesimpulanya.Populasi dalam penelitian ini adalah semua pasien yang berkunjung dan menggunakan jasa pelayanan di Puskesmas Karang Pule Kota Mataram yang berjumah 3518 pasien pada bulan Desember tahun 2018.

Sampel penelitian ini adalah sebagian yang diambil dari keseluruhan obyek yang diteliti dan dianggap mewakili populasi.Sampel ini diambil berdasarkan dua kriteria yaitu kriteria inkulis dan kriteria eksklusi inklusi. Kriteria inklusi adalah karakteristik umum dari suatu populasi target yang akan dijadikan subjek penelitian sedangkan kriteria eksklusi adalah 
menghilangkan beberapa subjek yang memenuhi kriteria inklusi dari penelitian dikarenakan kriteria dan sebab-sebab tertentu. Kriteria inklusi, meliputi pasien yang berusia $>18$ tahun dan $<80$ tahun serta bersedia di teliti. Sedangkan kriteria eksklusi, meliputi Pasien yang mengalami gangguan komunikasi dan Pasien yang mengalami gangguan kejiwaan atau cacat mental. Untuk menentukan ukuran sampel yang sudah diketahui jumlah populasinya yaitu 3518 sebanyak pasien dapat menggunakan rumus slovin (Notoatmodjo, 2010) :

$$
\begin{aligned}
& n=\frac{N}{1+N\left(d^{1}\right)^{2}} \\
& \text { Ket: } \\
& \mathrm{n}=\text { Sampel } \\
& \mathrm{N}=\text { Populasi } \\
& \mathrm{d}=\text { Derajatkepercayaan }(0,1) \\
& n=\frac{3518}{1+3518(0,1)^{2}} \\
& n=\frac{3518}{1+3518(0,01)^{2}} \\
& n=\frac{3518}{1+35,18} \\
& n=\frac{3518}{36,18} \\
& =97,24=97 \text { pasien }
\end{aligned}
$$

Jadi jumlah sampel yang akan digunakan dalam penelitian ini adalah sebanyak 97 pasien.

\section{Teknik Pengumpulan Data}

Teknik pengumpulan data adalah suatu proses pendekatan kepada subyek yang di perlukan dalam suatu penelitian. Dalam penelitian pengumpulan data dilakukan dengan menggunakan kuesioner berupa pertanyaan untuk petugas Tempat Pendaftaran Pasien (TPP) di Puskesmas Karang Pule Mataram dengan mengisi lembar kuisioner yang di isi oleh pasien.Serta melakukan wawancara terhadap pasien yang berhubungan dengan kualitas petugas di tempat pendaftaran pasien (TPP) rawat jalan.

\section{Analisis Data}

Analisis data yang dilakukan adalah analisis univariat yakni analisis yang dilakukan untuk satu atau tiap variabel dari hasil penelitian. Berdasarkan distribusi frekuensi analisis ini bertujuan untuk menjelaskan atau mendeskripsikan karakteristik setiap variabel penelitian. Analisis data akan digunakana yaitu SPSS (Statistical Package for the Social Sciences).

\section{HASIL DAN PEMBAHASAN}

Berikut ini akan diuraikan hasil dan pembahasan dari penelitian yang telah dilakukan

1. Identifikasi tingkat kepuasaan pasien.

Identifikasi tingkat kepuasan pasien terhadap pelayanan yang di berikan petugas pendaftran di Puskesmas Karang Pule Kota Mataram, berdasarkan 4 sikap positif komunikasi interpersonal.

a. Empati

Tabel 1. Penilaian Pelayanan Pendaftaran Pasien dari segi empati

\begin{tabular}{|l|c|c|}
\hline \multicolumn{1}{|c|}{ Kategori } & N & $\%$ \\
\hline Sangat Puas & 56 & 57,8 \\
\hline Puas & 36 & 37,1 \\
\hline Kurang Puas & 5 & 5,1 \\
\hline Total & 97 & 100 \\
\hline
\end{tabular}

Tabel diatas menunjukkan bahwa dari 97 responden memberikan tanggapan yang positif terhadap pelayanan di tempat pendaftaran pasien di Puskesmas Karang Pule Kota Mataram tersebut sebanyak 56 orang atau $57.8 \%$ responden yang menyatakan sangat puas, 36 orang atau $37.1 \%$ responden yang menyatakan puas dan 5 orang atau $5.1 \%$ yang menyatakan kurang puas terhadap pelayanan yang diberikan oleh petugas di tempat pendaftaran pasien di Puskesmas Karang Pule Kota Mataram. Dalam dimensi pelayanan empathy (kemauan personel untuk peduli dan memperhatikan setiap pelanggan) tersebut, responden menyatakan sangat puas terhadap pelayanan di loket pendaftaran terlihat bahwa petugas mampu melayani pasien dengan ramah tamah dan tidak membeda-bedakan antara pasien yang satu dengan yang lainnya artinya petugas 
memberikan pelayanan yang sama kepada semua pasiennya, serta petugas di loket pendaftaran tersebut juga berpenampilan yang rapi dan menarik.

b. Keterbukaan

Tabel 2. Penilaian Pelayanan Pendaftaran Pasien dari segi keterbukaan

\begin{tabular}{|l|c|c|c|}
\hline \multicolumn{1}{|c|}{ Kategori } & N & & $\%$ \\
\hline Sangat Puas & 33 & & 34.1 \\
\hline Puas & 57 & & 58.7 \\
\hline Kurang Puas & 7 & & 7.2 \\
\hline Total & 97 & & 100 \\
\hline
\end{tabular}

Tabel diatas menunjukkan bahwa dari 97 responden memberikan tanggapan yang positif terhadap pelayanan di tempat pendaftaran pasien di Puskesmas Karang Pule Kota Mataram tersebut. Sebanyak 33 orang atau 34.1\%, 57 orang atau $58.7 \%$ responden yang menyatakan puas, dan yang menyatakan kurang puas 7 orang atau $7.2 \%$ terhadap pelayanan yang diberikan oleh petugas di tempat pendaftaran Pasien di Puskesmas Karang Pule Kota Mataram. Dalam pelayanan tersebut yaitu kemampuan untuk menyampaikan informasi atau mmenerima pendapat, dimana sikap keterbukaan ini ditandai dengan bertanggung jawab atas apa yang menjadi tugas dan wewenang dari petugas puskesmas, serta menerima masukan atau kritik ketika ada pasien yang mengeluh atau melakukan komplain terhadap pelayanan puskesmas.

\section{c. Kesetaraan}

Tabel 3. Penilaian Pelayanan Pendaftaran Pasien dari segi kesetaraan

\begin{tabular}{|l|l|l|}
\hline \multicolumn{1}{|c|}{ Kategori } & \multicolumn{1}{c|}{ N } & $\%$ \\
\hline Sangat Puas & 56 & 57.8 \\
\hline Puas & 36 & 37.1 \\
\hline Kurang Puas & 5 & 5.1 \\
\hline Total & 97 & 100 \\
\hline
\end{tabular}

Tabel diatas menunjukkan bahwa dari 97 responden memberikan tanggapan yang positif terhadap pelayanan di tempat pendaftaran pasien di Puskesmas Karang Pule Kota Mataram tersebut. Sebanyak 56 orang atau $57.8 \%, 36$ orang atau $37.1 \%$ responden yang menyatakan puas, dan 5 orang atau $5.1 \%$ responden yang menyatakan kurang puas terhadap pelayanan yang diberikan oleh petugas di tempat pendaftaran pasien di Puskesmas Karang Pule Kota Mataram. Dalam Pelayanan tersebut sikap positif kesetaraan dalam hal kemampuan petugas puskesmas untuk memposisikan orang atau pasien dalam kesetaraan. Menyadari akan adanya kepentingan yang berbeda-beda dalam pasien, petugas puskesmas tidak boleh memaksakan kehendak kepada pasien dengan mengutamakan anggota keluarganya dalam proses pelayanan atau mengutamakan pejabat daerah dalam melakukan pelayanan, sikap kesetaraan ini juga ditandai dengan adanya komunikasi dua arah yang dilakukan petugas puskesmas dan pasien.

d. Dukungan

Tabel 4. Penilaian Pelayanan Pendaftaran Pasien dari segi dukungan

\begin{tabular}{|l|l|l|}
\hline \multicolumn{1}{|c|}{ Kategori } & \multicolumn{1}{c|}{ N } & \multicolumn{1}{c|}{$\%$} \\
\hline Sangat Puas & 35 & 36 \\
\hline Puas & 55 & 56.7 \\
\hline Kurang Puas & 7 & 7.6 \\
\hline Total & 97 & 100 \\
\hline
\end{tabular}

Tabel diatas menunjukkan bahwa dari 97 responden memberikan tanggapan yang positif terhadap pelayanan di tempat pendaftaran pasien di Puskesmas Karang Pule Kota Mataram tersebut. Sebanyak 35 orang atau $36 \%$ responden yang menyatakan sangat puas, 55 orang atau $56.7 \%$ responden yang menyatakan puas dan 7 orang atau $7.3 \%$ yang menyatakan kurang puas terhadap pelayanan yang diberikan oleh petugas di tempat pendaftaran pasien di Puskesmas Karang Pule Kota Mataram. Dukungan ini terlihat dari interaksi yang terbuka antara pasien dan petugas puskesmas dalam memberikan respon terhadap lawan bicara, terlihat pada saat pasien untuk registrasi berobat, keramahan petugas dengan memberikan senyum, salam, sapa diawal pelayanan pada 
pasien, sehingga pasien merasa di ayomi dan merasa difasilitas dengan baik.

2. Tingkat kepuasan pasien pada pelayanan di Puskesmas Karang Pule Kota Mataram.

Tabel 5. Tingkat Kepuasan Pasien terhadap

layanan pendaftaran

\begin{tabular}{|l|l|l|}
\hline \multicolumn{1}{|c|}{ Kategori } & \multicolumn{1}{c|}{ N } & \multicolumn{1}{c|}{$\%$} \\
\hline Sangat Puas & 67 & 69.1 \\
\hline Puas & 22 & 22.7 \\
\hline Kurang Puas & 8 & 8.2 \\
\hline Total & 97 & 100 \\
\hline
\end{tabular}

Tabel diatas menunjukkan bahwa dari 97 responden memberikan tanggapan yang positif atau menyatakan sangat puas terhadap pelayanan di tempat pendaftaran pasien di Puskesmas Karang Pule Kota Mataram tersebut. Sebanyak 67 orang atau $69.1 \%$ responden yang menyatakan sangat puas, 22 orang atau $22.7 \%$ responden yang menyatakan puas dan 8 orang atau $8.2 \%$ yang menyatakan kurang puas terhadap pelayanan yang diberikan oleh petugas di tempat pendaftaran pasien di Puskesmas Karang Pule Kota Mataram.

Menurut Kotler (dalam Lupiyoadi, 2013), kualitas pelayanan adalah keseluruhan ciri serta sifat dari suatu produk atau pelayanan yang berpengaruh pada kemampuannya untuk memuaskan kebutuhan yang dinyatakan atau tersirat. Dengan demikian, yang dimaksud dengan mutu pelayanan kesehatan adalah yang menunjukkan pada tingkat kesempurnaan pelayanan kesehatan dalam menimbulkan rasa puas pada diri setiap pasien.Berdasarkan hasil penelitian yang telah dilakukan di Puskesmas Karang Pule Kota Mataram khususnya di Tempat Pendaftaran Pasien, dapat diketahui bahwa secara keseluruhan respon masyarakat yang menggunakan pelayanan di Puskesmas tersebut menyatakan puas dengan pelayanan yang diberikan di puskesmas bersangkutan, karena responden merasa nyaman dengan pelayanan yang diberikan oleh petugas di puskesmas tersebut. Selain itu, ada juga pasien yang menyatakan tidak puas karena sebagian besar pasien lama menunggu pada saat dilayani di loket pendaftaran.

Pelayanan kesehatan akan dirasakan berkualitas oleh para pelanggannya jika penyampaiannya dirasakan melebihi harapan dan pengguna layanan. Penilaian para pengguna jasa pelayanan ditujukan kepada penyampaian jasa, kualitas pelayanan, atau cara penyampaian jasa tersebut kepada para pemakai jasa (Muninjaya, 2010).

Dengan demikian bahwa aktivitas dalam kualitas pelayanan berawal dari kemampuan komunikasi interpersonal menjadi sangat penting untuk dapat dipahami dan dikuasai dengan orang lain. Petugas dan pasien merupakan dua komponen yang berperang saling mendukung dalam berinteraksi. Jika salah satu komponen saja yang aktif tentunya tidak akan menghasilkan dampak yang maksimal.

\section{SIMPULAN DAN SARAN \\ Kesimpulan}

Berdasarkan penelitian yang telah dilakukan di Puskesmas Karang Pule Kota Mataram khususnya di Tempat Pendaftaran Pasien dengan jumlah responden sebanyak 97 responden, maka dapat disimpulkan bahwa:

1. Identifikasi komunikasi interpersonal berdasarkan tingkat kepuasan pelayanan di PuskesmasKaranng Pule Kota Mataram dapat dilihat dari 4 sikap positif dari masing-masing menunjukan bahwa :

a. Identifikasi gambaran komunikasi interpersonal petugas Puskesmas Karang Pule terahadap sikap empati sudah mencapai $57.8 \%$ atau 56 orang kategori sangat puas, $37.1 \%$ atau 36 orang kategori sangat puas dan $5.1 \%$ atau 5 orang dengan kategori kurang puas.

b. Identifikasi pola komunikasi interpersonal petugas Puskesmas Karang Pule terahadap sikap keterbukaan suda mencapai $58.7 \%$ atau 57 orang kategori puas, $34.1 \%$ atau 33 kategori sangat puas dan $7.2 \%$ atau 7 dengan kategori kurang puas.

c. Identifikasi pola komunikasi interpersonal petugas Puskesmas Karang Pule terahadap sikap kesetaraan sudah mencapai $57.8 \%$ 
atau 56 orang kategori sangat puas, $37.1 \%$ atau 36 kategori puas, dan $5.1 \%$ atau 5 dengan kategori kurang puas.

d. Identifikasi pola komunikasi interpersonal petugas Puskesmas Karang Pule terahadap sikap dukungan sudah mencapai $79.4 \%$ atau 77 orang kategori puas.

2. Gambaran tingkat kepuasan pelayanan di Puskesmas Karang Pule Kota Mataram menunjukan hasil bahwa $69.1 \%$ orang atau 67 reponden mengatakan sangat puas terhadap pelayanan yang di berikan oleh Puskesmas Karang Pule tersebut.

\section{Saran}

1. Sebaiknya puskesmas Karang Pule hendaknya mempertahankan dan meningkatkan kualitas pelayanan agar pasien merasa sangat puas dengan pelayanan yang diberikan.

2. Sebaiknya petugas pendaftaran di puskesmas dapat selalu memberikan $\mathrm{s}$ enyum, sapa dan salam pada saat melayani pasien agar kepuasan pasien di Tempat Pendaftaran Pasien di Puskesmas Karang Pule Kota Mataram tersebut terbilang memuaskan dan bahkan sangat memuaskan.

3. Bagi peneliti lain, diharapkan penelitian selanjutnya yang ingin meneliti dengan tema yang sama agar dapat memperbaiki kelemahan yang terdapat dalam penelitian ini yaitu salah satunya masih bersifat dekstriptif,sehingga lebih menyempurnakan alat ukur menggukan metode penelitian kualitatif agar dapat ditemukan faktorfaktor lain yang mempengerahui kepuasan pasien.

\section{UCAPAN TERIMA KASIH}

Saya menyampaikan penghargaan yang setinggi-tingginya dan ucapan terima kasih yang sebesar-besarnya kepada Direktur Politeknik Medica Farma Husada Mataram, Ketua Program Studi Rekam Medis dan Informasi Kesehatan, Bapak Ibu dosen Program Studi Rekam Medis dan Informasi Kesehatan, Kepala Puskesmas
Karang Pule Kota Mataram yang telah membimbing dan memberikan motivasi, semangat dan mendoakan yang terbaik untuk kemudahan penelitan ini, serta yang terakhir adalah informan atau pasien yang telah bersedia diwawancarai selama proses penelitian berlangsung.

\section{REFERENSI}

1. A.A. Gde Muninjaya.2010. Manajemen Kesehatan, Jakarta : Penerbit Buku Kedokteran

2. Departemen Kesehatan RI. 2014. Peraturan Menteri Kesehatan Republik Indonesia Nomor 9 Tahun 2014 Tentang Klinik. Jakarta.

3. Efendi, Ferry \& Makhfud.2009. Keperawatan Kesehatan Komunitas Teori dan. Praktik dalam Keperawatan. Jakarta: Salemba Medika.

4. Kamila, M., 2018. Tinjauan Ketidaklengkapan Syarat Klaim BPJS (Badan Penyelenggara Jaminan Sosial) di Unit Rawat Inap Rumah Sakit Patut Patuh Pathu Gerung, Karya Tulis Ilmiah, Politeknik "Medica Farma Husada" Mataram.

5. Kuntoro, W., dan Istiono, W., 2017. Kepuasaan Pasien Terhadap Kualitas Pelayanan di Tempat Pendaftaran Pasien Rawat Jalan Puskesmas Kretek Bentul Yogyakarta. Jurnal Kesehatan

6. Linda Prasetia.2018.Kepuasan Pasien Terhadap Pelayanan Kesehatan: Studi Deksriptif pada klinik UIN Sunan Ampel.Surabaya.Journal of Health Science and prevention

7. Lupiyordi, R. 2013. Manajemen Pemasaran Jasa.Jakarta:Salemba Empat

8. Morissan M.,dkk.2012. Metode Penelitian Survei. Jakarta: Kencana

9. Notoadmodjo, S. 2010. Metodologi Penelitian Kesehatan. Jakarta: Rineka Cipta

10. Rangkuti, F.2013. Measuring Customer Satisfaction. Jakarta: Gramedia Pustaka Utama.

11. Sugiyono. 2010. Metode Penelitian Pendidikan Pendekatan Kuantitatif, kualitatif, dan R\&D. Bandung: Alfabeta.

12. Suranto.2011. Komunikasi Interpersonal. Yogyakarta: Graha Ilmu. 